\title{
Imitative learning in Japanese quail (Coturnix japonica) using the bidirectional control procedure
}

\author{
CHANA K. AKINS, EMILY D. KLEIN, and THOMAS R. ZENTALL \\ University of Kentucky, Lexington, Kentucky
}

\begin{abstract}
In the bidirectional control procedure, observers are exposed to a conspecific demonstrator responding to a manipulandum in one of two directions (e.g., left vs. right). This procedure controls for socially mediated effects (the mere presence of a conspecific) and stimulus enhancement (attention drawn to a manipulandum by its movement), and it has the added advantage of being symmetrical (the two different responses are similar in topography). Imitative learning is demonstrated when the observers make the response in the direction that they observed it being made. Recently, however, it has been suggested that when such evidence is found with a predominantly olfactory animal, such as the rat, it may result artifactually from odor cues left on one side of the manipulandum by the demonstrator. In the present experiment, we found that Japanese quail, for which odor cues are not likely to play a role, also showed significant correspondence between the direction in which the demonstrator and the observer push a screen to gain access to reward. Furthermore, control quail that observed the screen move, when the movement of the screen was not produced by the demonstrator, did not show similar correspondence between the direction of screen movement observed and that performed by the observer. Thus, with the appropriate control, the bidirectional procedure appears to be useful for studying imitation in avian species.
\end{abstract}

Although the study of imitation in animals can be traced at least as far back as Thorndike (1898), research on imitative learning in animals has seen renewed interest in recent years (Galef, 1998; Heyes \& Galef, 1996; Zentall \& Galef, 1988). This resurgence of research interest can be attributed to the development of procedures that distinguish imitative learning from other socially mediated and attentional behavior (e.g., contagion, social facilitation, local and stimulus enhancement, and object movement reenactment).

Stimulus enhancement is one of the most persistent alternative accounts of what has been presumed to be imitative learning. Stimulus enhancement may be present when the facilitation of acquisition by the observer can be attributed to the increased attention to a stimulus or manipulandum resulting from the behavior of a demonstrator (see Denny, Clos, \& Bell, 1988; Galef, 1988; Zentall \& Levine, 1972). An appropriate means of controlling for such enhancement was originally reported by Dawson and Foss (1965; see also Galef, Manzig, \& Field, 1986). In this

This research was supported by National Science Foundation Grant IBN 941489 and National Institute of Mental Health Grants MH55118 and MH59194 to T.R.Z. and National Science Foundation Grant IBN9511656to C.K.A. We thank Angela Nichols, Monica Westin, and Carla Steger for their help with experimental sessions. Correspondence should be addressed to T. R. Zentall, Department of Psychology, University of Kentucky, Lexington, KY 40506-0044 (e-mail: zentall@ pop.uky.edu). design, known as the two-action method, one of two different means of achieving the same outcome is demonstrated to an observer by a member of the same species (a conspecific). The two-action method does not require the inclusion of a social facilitation control group to determine the effect of the mere presence of another animal on the acquisition of the target behavior, because all the groups observe a demonstrator. In addition, the two-action method controls for possible stimulus enhancement effects, because all the observers are exposed to demonstrators that interact with the same manipulandum (i.e., increased attention to the manipulandum should affect all animals equally).

Recently, the two-action method has been used to demonstrate imitative learning in Japanese quail (Coturnixjaponica; Akins \& Zentall, 1996, 1998; Dorrance \& Zentall, 2001), as well as in pigeons (Zentall, Sutton, \& Sherburne, 1996). In these studies, birds that had observed demonstrators pecking at a treadle (a small platform near floor level) for food reward mostly pecked the treadle when given access to it, whereas birds that had observed demonstrators stepping on the treadle mostly stepped on the treadle. The two-action method has been criticized, however, on the grounds that birds may naturally step on the treadle in this apparatus, just as they might scratch the ground while foraging for food. Thus, the stepping response may not be acquired through imitation but could occur naturally through trial and error learning. Furthermore, the birds that 
are permitted to observe another bird pecking may show contagious pecking behavior that is directed at the treadle through local enhancement (attention directed at the treadle by its movement; Campbell, Heyes, \& Goldsmith, 1999; Kaiser, Zentall, \& Galef, 1997). However, it should be noted that contagious behavior generally occurs contemporaneously with its occurrence in others. Furthermore, no evidence for natural treadle-stepping behavior was found by Kaiser et al. On the other hand, it may be that a more symmetrical version of the two-action method, the bidirectional control procedure, developed by Heyes and Dawson (1990), would provide a procedure for the study of imitative learning in animals less prone to interpretation in terms of naturally occurring behavior.

Inspired by an apparatus originally developed by Grindley (1932) to study instrumental conditioning in guinea pigs, Heyes and Dawson (1990) trained demonstrator rats to push an overhead rod either to the left or to the right. Hungry rats then observed a demonstrator push the rod in one direction, after which they were given access to the rod and were rewarded for pushes in either direction. Heyes and Dawson found that the observer rats showed a significant tendency to push the rod in the same direction as that in which they had observed it being pushed. Further evidence that the relative direction of the demonstrator's push determined the direction of the observer's push was reported by Heyes, Dawson, and Nokes (1992). These researchers found that observer rats continued to push the rod in the same direction as did the demonstrators, even when the overhead rod was moved $90^{\circ}$ to an adjacent side of the demonstration chamber, immediately following observation of the demonstrator.

It has been suggested that the bidirectional control procedure can provide a useful means of assessing imitative learning because there is generally an equal likelihood of occurrence of the two actions (Boysen \& Himes, 1999). Thus, the bidirectional control procedure allows for a degree of response symmetry (it should be just as easy to operate the manipulandum in one direction as in the other) typically not present when the two responses require manipulation with different parts of the body (e.g., pecking vs. stepping on a treadle), more typical of procedures involving the two-action method. On the other hand, it should be noted that whether the two responses have equal probability of occurrence or not is not critical, as long as the direction of the demonstration is counterbalanced.

More recently, however, the basis of the results of experiments using the bidirectional control procedure with rats has been questioned. Specifically, Mitchell, Heyes, Gardner, and Dawson (1999) proposed that olfactory cues, rather than visual cues, may have been responsible for what appeared to have been imitative learning in earlier research. These authors found that when they rotated (twisted) the overhead rod $180^{\circ}$ along its axis between the time of observation and that of performance by the observer, the observers tended to push the rod in the direction opposite from the direction they had observed it pushed. The only effect that rotation had on the rod was to move the surface of the rod pushed by the demonstrator to the oppo- site side, relative to the rest of the chamber. The authors concluded that during the observation period, odor cues had likely been deposited by the demonstrator on the side of the rod that it had pushed and that these odors probably attracted the interest of the observers so that they made contact with the rod on the side with the odors. However, Mitchell et al. suggested that because birds rely primarily on visual rather than olfactory cues, they would be more appropriate subjects in imitative learning experiments in which the bidirectional control procedure is used.

Japanese quail, already mentioned for their use in imitative learning experiments, are a social, precocially active bird and, thus, are likely to attend to the behavior of conspecifics. Furthermore, males of this species, known to be quite territorial (Sachs, 1966), presumably are motivated to attend to other males in close proximity. Although there is evidence that quail possess an olfactory epithelium (Fitzgerald, 1969), there is little evidence that they make use of olfactory cues.

The purpose of the present experiment was to assess imitative behavior by using a bidirectional control procedure in a primarily visual species. Rather than using an overhead rod as a manipulandum, we adopted a variation of a task used by Powell and Kelly (1975) to investigate tool use in crows. Our apparatus involved a metal screen that covered the opening to a standard bird feeder used in operant research. Each quail observer could watch a conspecific demonstrator in an adjacent chamber push a screen either to the left or to the right to obtain food from a lit and raised feeder. The observers were then placed in the demonstrator's chamber and were free to push the screen in either direction while the feeder was lit and raised.

Finally, in any imitation experiment in which the action of the demonstrators may have different effects on the environment (e.g., a screen that is pushed to the left vs. a screen that is pushed to the right), there is concern that the observers may learn differentially about how the screen works (i.e., the screen can slide to the left or it can slide to the right). Thus, observers may learn what change in the environment is needed for reward to be obtained. This form of nonimitative learning has been referred to as the emulation of affordances (Tomasello, 1996) or as $o b$ ject movement reenactment (Custance, Whiten, \& Fredman, 1999). To control for this kind of learning, we included observers that were exposed to demonstrators that had been trained to stand away from the screen while it was being moved to the left or the right side unobtrusively by the experimenter. The degree to which the observers in the control group pushed the screen in the same direction as that in which they had seen it move (but not pushed by the "demonstrator" quail) served as a baseline against which to assess imitative learning by the two experimental groups (observe push left and observe push right).

\section{METHOD}

\section{Subjects}

Twenty-eight male Japanese quail, approximately 9-12 months old, served as subjects. Eight quail served as demonstrators. The 
remaining quail served as observers. The birds were hatched from eggs obtained from a randomly bred colony maintained at the University of Kentucky and were raised in mixed-sex groups in brooders until the age of 4-5 weeks, when they were moved to individual wiremesh quail cages (GQF Manufacturing Co., Savannah, GA). During the experiment, the subjects were maintained at $80 \%-85 \%$ of their ad-lib body weight. All the birds had previously served as subjects in a Pavlovian conditioning experiment in which they had been provided sexual opportunity with female birds. The colony room was maintained under a 16:8-h light:dark cycle. Water was freely available in the home cage.

\section{Apparatus}

The apparatus used in the present experiment was a modification of that used by Akins and Zentall (1996). It consisted of two large modular chambers (Coulbourn Instruments, Lehigh Valley, PA), each measuring $30.5 \mathrm{~cm}$ high, $25.5 \mathrm{~cm}$ wide, and $28.0 \mathrm{~cm}$ deep (see Figure 1). The demonstrator's chamber contained a rectangular feeder opening and a houselight. The feeder opening was covered with a $7.6 \mathrm{~cm}$ high $\times 5.0 \mathrm{~cm}$ wide wire-mesh screen. The wires were spaced $1.5 \mathrm{~cm}$ apart horizontally and $2.5 \mathrm{~cm}$ apart vertically. The screen could be moved to the left or to the right along tracks above and below the screen. A stiff wire attached to the right side of the screen extended through the exterior wall of the demonstrator's chamber. The wire enabled the experimenter to push the screen to the left or pull the screen to the right unobtrusively (out of sight of the quail). Movable stops, placed strategically along the wire, kept the demonstrators from pushing the screen in the unassigned direction. The stops were not used during testing. The subjects could gain access to food (Southern States 40\% Poultry Supplement) through the feeder opening when the feeder tray was raised and illuminated by the feeder light and the screen was pushed to either side of the feeder opening. A houselight $(28 \mathrm{~V}, 0.1 \mathrm{~A})$ mounted near the ceiling of the chamber above the feeder opening provided illumination of the demonstrator's chamber.

The observer's chamber was attached to the demonstrator's chamber (on the left side facing the feeder). The common wall of both chambers was made of transparent Plexiglas, allowing observers visual access to the demonstrator's chamber. The observer's chamber did not contain a feeder opening or a houselight, and it was always dark to facilitate observation of the demonstrator by the observer. The dark observer side also reduced the visibility of the observer by the demonstrator.

\section{Procedure}

Four quail served as demonstrators for the imitation condition. They were magazine trained and shaped by successive approximations to push the screen with their beaks either to the right side $(n=$ $2)$ or to the left side $(n=2)$ of the feeder opening. On each trial, the feeder was raised and illuminated. When the quail inserted its head into the feeder, it broke a photo beam, which started a 3-sec interval. At the end of $3 \mathrm{sec}$, the feeder was lowered, the feeder light was turned off, and the screen was moved back in front of the feeder opening. After a 10-sec intertrial interval, the feeder was once again raised, and the feeder light was turned on. In order for the quail to insert their beaks sufficiently far into the feeder to obtain food, they needed to stand directly in front of the feeder regardless of which direction they were required to push the screen. During the last few days of training, a dummy bird (a live bird that was neither an observer nor a demonstrator) was placed in the observer's chamber while each demonstrator performed. Exposure to a conspecific during training served to ensure that the presence of the observer would not disrupt the demonstrator's performance during the observation period.

Four other quail served as demonstrators for the control condition. They were trained as were the other demonstrators, with the following exceptions. When the feeder was raised, these demonstrators were trained to stand away from the screen until it was opened. For these demonstrators, the screen was opened either to the left $(n=2)$ or to the right $(n=2)$ by the experimenter. These demonstrators provided a control for social effects (mere presence) and for observation of the movement of the screen (object movement reenactment).

The observers were feeder trained in the demonstrator's chamber with the screen already pushed to one side of the feeder opening (the side was randomly selected prior to each feeder-training session). The criterion for magazine training was the reliable insertion of the quail's head into the feeder within $1 \mathrm{sec}$ of raising the lit feeder, 24 consecutive times. All the observers were then given a minimum of 4 days of habituation to the observer's chamber to ensure that they would not be frightened when placed in the chamber for their observation session. The assignment of observers to

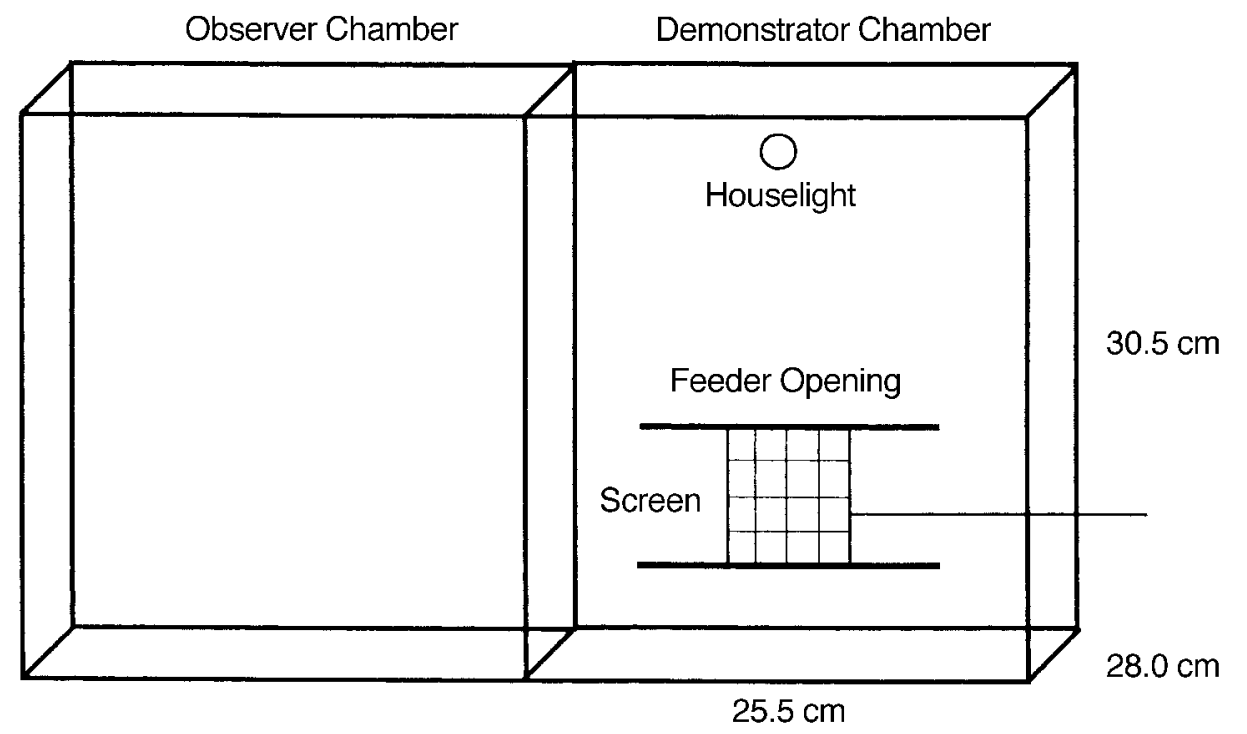

Figure 1. Schematic of the apparatus used in the experiment. 
demonstrators was random. One observer originally assigned to a right-pushing demonstrator was inadvertently exposed to a leftpushing demonstrator. Thus, 6 observers watched a demonstrator push the screen to the left of the feeder opening, whereas the other 4 observers watched a demonstrator push the screen to the right of the feeder opening. Five control observers watched the screen move to the left in the presence of a control (nonpushing) demonstrator, and 5 control observers watched the screen move to the right in the presence of a control demonstrator.

During a test session, an observer was placed in the observer's chamber while the demonstrator performed 48 screen pushes (trials) in the assigned direction (imitation condition) or the demonstrator waited for the screen to open in the assigned direction (control condition). The observation period took between 6 and $12 \mathrm{~min}$. Immediately following the 48th trial, the demonstrator was removed, and the observer was placed in the demonstrator's chamber for $20 \mathrm{~min}$. During the 20-min test session, each screen push to the left or the right of the feeder opening was rewarded and recorded. A push to the left or right of the feeder opening was counted if a subject pushed the screen sufficiently for it to insert its head into the feeder opening and eat from the feeder. Thus, right and left pushes were easily distinguishable. The .05 level of statistical significance was used for all analyses of the results.

\section{RESULTS}

\section{Direction of First Push}

During the test session, the first response for 8 of the 10 observers in the imitation condition was made in the same direction as their demonstrator (all 4 of the right-pushing observers and 4 of the 6 left-pushing observers). The firstresponse data provide a good estimate of the overall tendency to respond to the screen by observers in the two observation conditions. A chi-square analysis preformed on the first-response data indicated that the difference was statistically different from chance $\left[\chi^{2}(1)=4.45\right]$. Thus, the first response made by the imitation observers was reliably predicted by the response that their demonstrator had made during the observation period.
The first response data for quail in the control condition were less consistent. The first response for 7 of the 10 quail was made in the opposite direction from the direction they had seen it move (4 birds in the screen-left group and 3 birds in the screen-right group; 1 bird did not push the screen at all); however, a chi-square analysis preformed on the first-response data for the control condition indicated that the difference was not statistically different from chance $\left[\chi^{2}(1)=2.43\right]$.

\section{Mean Screen Pushes}

The mean total screen pushes made by the observers in the imitation condition $(M=21.7)$ was comparable to the mean total screen pushes made by the observers in the control condition $(M=23.3)$. However, the distribution of those responses was quite different for the two conditions. The quail in the imitation condition pushed the screen in the same direction as that in which they had seen it pushed an average of 15.8 times, whereas they pushed it in the other direction an average of only 5.9 times. On the other hand, quail in the control condition pushed the screen in the same direction as that in which they had seen it pushed an average of only 9.8 times, whereas they pushed it in the other direction a average of 13.5 times (see Table 1).

A three-way mixed-effect analysis of variance (ANOVA) was performed on the number of screen pushes for each group, with condition (imitation vs. control) and direction observed (observe screen move left vs. observe screen move right) as the independent factors and matching (whether the performed pushes matched or did not match the direction that had been observed) as the repeated factor. The analysis indicated that only the condition $\times$ matching interaction $[F(1,16)=8.54]$ and the direction observed $\times$ matching interaction $[F(1,16)=11.40]$ were significant. None of the main effects or other interactions was statistically reliable (all $F \mathrm{~s}<2.26$ ). The significant

Table 1

Screen Push Responses by Individual Quail in the Imitation and Control Conditions

\begin{tabular}{|c|c|c|c|c|c|c|c|c|c|}
\hline \multicolumn{5}{|c|}{ Imitation Condition } & \multicolumn{4}{|c|}{ Control Condition } & \multirow[b]{2}{*}{$\begin{array}{c}\text { Proportion of } \\
\text { Match }\end{array}$} \\
\hline Subject & Match & Nonmatch & Total & $\begin{array}{c}\text { Proportion of } \\
\text { Match }\end{array}$ & Subject & Match & Nonmatch & Total & \\
\hline \multicolumn{10}{|c|}{ Push Left } \\
\hline IL1 & 13 & 12 & 25 & .52 & CL1 & 3 & 22 & 25 & .12 \\
\hline IL2 & 21 & 8 & 29 & .72 & CL2 & 0 & 0 & 0 & - \\
\hline IL3 & 12 & 8 & 20 & .60 & CL3 & 9 & 22 & 31 & .29 \\
\hline IL4 & 12 & 10 & 22 & .55 & CL4 & 11 & 19 & 30 & .79 \\
\hline IL5 & 6 & 4 & 10 & .60 & CL5 & 0 & 33 & 33 & .00 \\
\hline IL6 & 10 & 3 & 13 & .77 & & & & & \\
\hline \multicolumn{10}{|c|}{ Push Right } \\
\hline IR1 & 46 & 0 & 46 & 1.00 & CR1 & 10 & 12 & 22 & .45 \\
\hline IR2 & 14 & 0 & 14 & 1.00 & CR2 & 14 & 4 & 18 & .78 \\
\hline IR3 & 22 & 11 & 33 & .67 & CR3 & 4 & 5 & 9 & .44 \\
\hline IR4 & 2 & 0 & 2 & 1.00 & CR4 & 26 & 7 & 33 & .79 \\
\hline & & & & & CR5 & 21 & 11 & 32 & .66 \\
\hline$M$ & 15.8 & 5.9 & 21.7 & .725 & & 9.8 & 13.5 & 23.3 & .433 \\
\hline$S E( \pm)$ & 3.86 & 1.51 & 4.01 & .061 & & 2.75 & 3.25 & 3.57 & .100 \\
\hline
\end{tabular}

Note-IL, imitation left; IR, imitation right; CL, control left; CR, control right. 


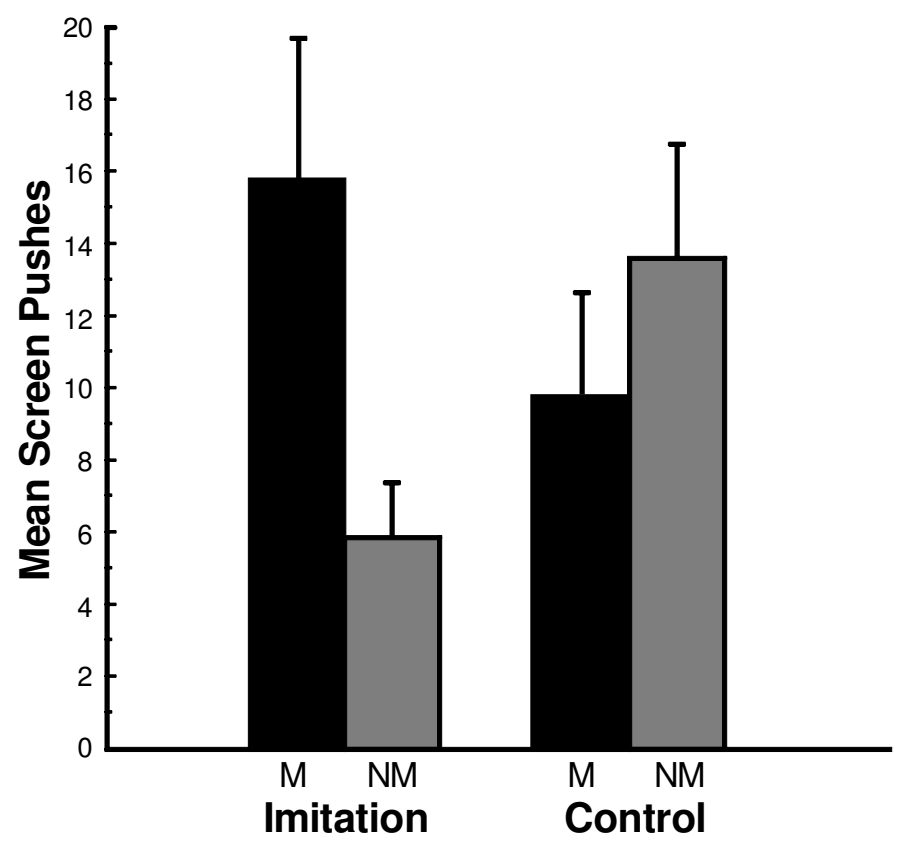

Figure 2. Mean number of screen pushes by Japanese quail in the imitation condition (in which a demonstrator quail had been observed to push the screen to the left or to the right) and quail in the control condition (in which the screen had been observed to move to the left or to the right in the presence of a conspecific). Screen pushes are distinguished by those that matched the observed direction of screen movement $(M)$ and those that did not match the observed direction of screen movement (NM). An error bar represents the standard error of the mean.

condition $\times$ matching interaction resulted from the fact, already noted, that the quail in the imitation condition matched considerably more than they did not match, whereas there was little difference between matching and nonmatching responses for the quail in the control condition. The interaction can been seen graphically in Figure 2 . The significant direction observed $\times$ matching interaction resulted from the fact that the quail showed a reliable bias to push the screen to the right (mean right pushes $=15.0$, mean left pushes $=7.4$ ). This bias resulted in a greater tendency for the quail to match when they observed the screen move to the right (17.7 vs. 5.6, respectively) and to mismatch when they observed the screen move to the left (12.8 vs. 8.8 , respectively), irrespective of condition.

The mean proportion of responses made to the left and right by the observers in each group provides a good comparative measure of imitative learning. Use of proportion of responses as a dependent measure controls for individual differences in total responding produced by differences in motivation or differences in habituation to the apparatus. The mean proportion of left-push responses by quail that observed a left-pushing demonstrator was .63, whereas the mean proportion of right-push responses by quail that observed a right-pushing demonstrator was .92. The proportion of matching responses for the control condition was much more dependent on direction. The mean proportion of left-push responses by the quail in the con- trol condition in which the screen had been observed to move to the left was .30 , whereas the mean proportion of right-push responses by the quail in the control condition in which the screen has been observed to move to the right was .62. Overall, the mean proportion of observers' responses that matched that of their demonstrators was .72, for the quail in the imitation condition. However, for the quail in the control condition, the mean proportion of observers' responses that matched the direction that the screen moved during observation was .43. Thus, the quail in the imitation condition pushed the screen in the direction that they had seen it pushed, proportionally, almost three times as often as in the other direction, whereas quail in the control condition pushed the screen in the direction that they saw it move, proportionally, about as often as they pushed it in the other direction. A summary of the data for individual quail appears in Table 1.

A two-way ANOVA performed on the proportion-ofmatching-response scores, with condition (imitation vs. control) and direction observed (observe screen move left vs. observe screen move right) as factors, indicated that the mean proportion of responses in the direction observed was significantly greater in the imitation condition (.72) than in the control condition $[.43 ; F(1,15)=24.65]$. In addition, there was a significant effect of direction observed $[F(1,15)=24.26]$. The observers pushed the screen proportionately more often to the right (.62). Separate analy- 
ses performed on the proportion of matching responses for the imitation condition for right-pushing observers and left-pushing observers indicated that both proportions were significantly different from chance $[F(1,5)=9.75$ and $F(1,3)=21.83$, respectively].

\section{DISCUSSION}

The present findings indicate than an avian species, such as the Japanese quail, which is primarily a visual animal, can show imitative learning when the bidirectional control procedure developed by Heyes and Dawson (1990) is used. Heyes (1996) suggested that the bidirectional control procedure controls not only for effects of social facilitation (the mere presence of a conspecific), but also for both local enhancement (the possibility that the demonstrator's behavior may draw the attention of the observer to the location at which the demonstrator is performing) and stimulus enhancement (the possibility that the demonstrator's behavior may draw the attention of the observer to the stimulus that the demonstrator is manipulating). The design of the present experiment also ruled out the possibility that object movement reenactment (learning how the environment works) could account for the differences in matching versus nonmatching behavior by the quail in the imitation condition. The quail in the imitation condition showed a significant tendency to match the direction of screen push that had been demonstrated. When the quail observed the screen moving but the demonstrator did not move it, the observers were no more likely to match than to mismatch the direction in which the screen had moved.

Although screen push responses to the left and right were expected to be equally probable in the absence of imitation, it appears that right pushes were more likely to be made than left pushes. This difference can be attributed to the fact that the door of the performance chamber through which the birds were introduced and removed was to the right of the wall of the chamber that contained the feeder and the quail tended to prefer the other side of the chamber. Also, the wire that allowed the experimenter to move the screen was attached to the right side of the screen, and some of the quail may have preferred the side without the wire. However, despite this bias, there was a strong tendency for the quail in the imitation condition to match the behavior of the demonstrators, regardless of the side of the screen that the demonstrators pushed.

The present results demonstrate that imitative learning can be found under conditions other than the two-action method reported by Akins and Zentall (1996, 1998; see also Dorrance \& Zentall, 2001; Zentall et al., 1996) in which birds that observed a stepping demonstrator learned to step on the treadle to obtain food, whereas those that observed a pecking demonstrator learned to peck at the treadle to obtain food. The bidirectional control procedure offers an alternative approach to the study of imitative learning in animals to the two-action method. In the case of the two-action method, it has been suggested that birds may naturally step on the treadle (whether they observe stepping or not) and that observation of pecking by a demonstrator may elicit pecking in the observer (contagion) that is directed toward the treadle via local enhancement (Campbell et al., 1999; Kaiser et al., 1997). In the case of the bidirectional control procedure, however, because the two responses studied (push right and push left) should be controlled by similar underlying mechanisms, such an alternative account is not possible.

\section{REFERENCES}

AKins, C. K., \& Zentall, T. R. (1996). Imitative learning in male Japanese quail (Coturnix japonica) involving the two-action method. Journal of Comparative Psychology, 110, 316-320.

AKIns, C. K., \& Zentall, T. R. (1998). Imitation in Japanese quail: The role of reinforcement of demonstrator responding. Psychonomic Bulletin \& Review, 5, 694-697.

Boysen, S. T., \& Himes, G. T. (1999). Current issues and emerging theories in animal cognition. Annual Review of Psychology, 50, 683-705.

Campbell, F. M., Heyes, C. M., \& Goldsmith, A. R. (1999). Stimulus learning and response learning in the European starling, in a twoobject/two-action test. Animal Behaviour, 58, 151-158.

Custance, D. M., Whiten, A., \& Fredman, T. (1999). Social learning of artificial fruit processing in enculturated capuchin monkeys. Journal of Comparative Psychology, 113, 13-23.

DAwson, B. V., \& Foss, B. M. (1965). Observational learning in budgerigars. Animal Behaviour, 13, 470-474.

Denny, M. R., Clos, C. F., \& Bell, R. C. (1988). Learning in the rat of a choice response by observation of S-S contingencies. In T. R. Zentall \& B. G. Galef, Jr. (Eds.), Social learning: Psychological and biological perspectives (pp. 207-223). Hillsdale, NJ: Erlbaum.

Dorrance, B. R., \& ZeNTALl, T. R. (2001). Imitative learning in Japanese quail depends on the motivational state of the observer at the time of observation. Journal of Comparative Psychology, 115, 62-67.

FitzGerald, T. C. (1969). The Coturnix quail: Anatomy and histology. Ames: Iowa State University Press.

GALEF, B. J., JR. (1988). Imitation in animals: History, definition, and interpretation of data from the psychological laboratory. In T. R. Zentall \& B. G. Galef, Jr. (Eds.), Social learning: Psychological and biological perspectives (pp. 3-28). Hillsdale, NJ: Erlbaum.

GALEF, B. J., JR. (1998). Recent progress in studies of imitation and social learning in animals. In M. Sabourin, F. I. M. Craik, \& M. Robert (Eds.), Advances in psychological science: II. Biological and cognitive aspects (pp. 275-299). Hove, U.K.: Psychology Press.

Galef, B. J., JR., MANZIG, L. A., \& Field, R. M. (1986). Imitation learning in budgerigars: Dawson and Foss (1965) revisited. Behavioral Processes, 13, 191-202.

GRINDLEY, G. C. (1932). The formation of a simple habit in guinea-pigs. British Journal of Psychology, 23, 127-147.

Heyes, C. M. (1996). Genuine imitation? In C. M. Heyes \& B. G. Galef, Jr. (Eds.), Social learning in animals: The roots of culture (pp. 371389). San Diego: Academic Press.

Heyes, C. M., \& Dawson, G. R. (1990). A demonstration of observational learning in rats using a bidirectional control. Quarterly Journal of Experimental Psychology, 42B, 59-71.

Heyes, C. M., DAwson, G. R., \& NoKes, T. (1992). Imitation in rats: Initial responding and transfer evidence. Quarterly Journal of Experimental Psychology, 45B, 59-71.

Heyes, C. M., \& GALEF, B. G., JR. (Eds.) (1996). Social learning in animals: The roots of culture. San Diego: Academic Press.

Kaiser, D. H., Zentall, T. R., \& Galef, B. G., JR. (1997). Can imitation in pigeons be explained by local enhancement together with trial and error learning? Psychological Science, 8, 459-465.

Mitchell, C. J., Heyes, C. M., Gardner, M. R, \& Dawson, G. R. (1999). Limitations of a bidirectional control procedure for the inves- 
tigation of imitation in rats: Odour cues on the manipulandum. Quarterly Journal of Experimental Psychology, 52B, 193-202.

Powell, R W., \& Kelly, W. (1975). A method for the objective study of tool-using behavior. Journal of the Experimental Analysis of Behavior, 24, 249-253.

SACHS, B. D. (1966). Sexual aggressive interactions among pairs of quail (Coturnix coturnix japonica). American Zoologist, 6, 559.

Thorndike, E. L. (1898). Animal intelligence: An experimental study of the associative processes in animals. Psychological Review Monograph Supplements, 2 (4), 1-109.

Tomasello, M. (1996). Do Apes ape? In C. M. Heyes \& B. G. Galef, Jr.
(Eds.), Social learning in animals: The roots of culture (pp. 319-346). San Diego: Academic Press.

Zentall, T. R., \& Galef, B. G., JR. (Eds.) (1988). Social learning. Psychological and biological perspectives. Hillsdale, NJ: Erlbaum.

ZENTALL, T. R., \& Levine, J. M. (1972). Observational learning and social facilitation in the rat. Science, 178, 1220-1221.

Zentall, T. R., Sutton, J. E., \& Sherburne, L. M. (1996). True imitative learning in pigeons. Psychological Science, 7, 343-346.

(Manuscript received June 4, 2001;

revision accepted for publication April 22, 2002.) 